Publisher homepage: www.universepg.com, ISSN: 2707-4668 (Online) \& 2707-465X (Print)

https://doi.org/10.34104/ajssls.022.012017

\section{Asian Journal of Social Sciences and Legal Studies}

Journal homepage: www.universepg.com/journal/ajssls
Asian Journat of Social Sciences and Legal Studies

\title{
Prestige Restoration According to Afghan Legal System
}

\section{Pasoon Miakhil ${ }^{1}$, Attaullah Naeemi ${ }^{2}$, and Ali Ahmad Bahar ${ }^{3}$}

${ }^{1}$ Dept. of Jurisdiction and Prosecution, Faculty of Law and Political Sciences, Sheikh Zayad University, Afghanistan; ${ }^{2}$ Dept. of Islamic Culture, Faculty of Sharia, Nangarhar University, Afghanistan; and ${ }^{3}$ Dept. of Fiqh and law, Faculty of Sharia, Said Jamaluddin University, Kunar, Afghanistan.

*Correspondence: pasoonwafamiakhil@yahoo.com (Pasoon Miakhil, Teaching Assistant, Dept. of Jurisdiction and Prosecution, Faculty of Law and Political Sciences, Sheikh Zayad University, Afghanistan).

\begin{abstract}
Prestige Restoration is the means by which the convicted person returns to original state after being charged and convicted, and the convicted person acts to restore his or her dignity after serving imprisonment or punishment through legal and judicial channels. There several conditions for the restoration of prestige according to law, which are; to serve whole punishment, amnesty and mitigation of punishment, or suspension of punishment. In addition, two types of restoration of dignity are considered; restoration of dignity based on the law, and restoration of dignity according to the judiciary; or Legal restoration dignity and judicial restoration of dignity.
\end{abstract}

Keywords: Restoration, Prestige, Convicted, Legal restoration, and Judicial restoration of prestige.

\section{INTRODUCTION:}

Prestige restoration is a judicial base that allows a person to obtain all the rights, which he or she has lost as a result of a judicial conviction according to law. The purposes of prestige restoring are to eliminate the effects of a conviction, to prevent others from propounding these effects, and to eliminate future deprivations based on a criminal conviction.

When a person is convicted after committing felony or misdemeanor based on the court order and serves the imprisonment, or being forgave after serving apportion of sentence; he or she can ask for restoration of prestige after the last date of his criminal conviction. According to the system of Criminal Law, the restoration of prestige or deprivation of social rights is also achieved after the elapse of time. Nonetheless in the Islamic system, the criminal sentences have no consequential effects excluding some exceptional and limited cases; and that is why the prestige of the convict is restored after serving the sentence, or after the expiration of the sentence. There are two types of prestige restoration; legal restoration of prestige and judicial restoration of UniversePG I www.universepg.com prestige. In legal restoration of prestige; the law has set a specific period for crimes, after expiration of period the person's prestige is restored. However, judicial restoration of prestige is grounded on the court ruling hence the convict's request, provided that the convict has served a particular duration of imprisonment. If the convict has died, the judicial restoration of prestige can be done by the heirs of convict. The rules for judicial prestige rest-oration are differing from the rules for legal prestige restoration. The Judicial Prestige restoration occurs when the accused behaves well; while the legal prestige restoration is achieved automatically after the expiration of the sentence, provided that the convicted does not commit any other crime during this period (Guldozian \& Iraj, 1388).

\section{METHOLODOGY:}

This research is carried out based of librarian and descriptive methods. The articles of laws that need clarity are explained. The restoration of prestige is clarified firstly, then the forms of restoration of prestige are explained, later we have continuously discussed the procedures of judicial restoration of pres- 
tige, which is essential for judicial restoration of prestige.

\section{Goals of the Research}

Each research is done to achieve some goals; our main goals for this research are:

1) To understand the notion of restoration of prestige.

2) To realize the contrast between Legal Restoration of Prestige and Judicial Restoration of Prestige.

3) To know the period that law stipulates for the restoration of prestige of a conditionally released person.

\section{Concept of Restoration of Prestige}

Restoration of prestige is a means through which the efficacies of a criminal conviction are removed and the convict receives original status. In fact, restoration of prestige is a remit of the competence of the convict that is lost because of committing the crime. When an individual is convicted after committing felony or misdemeanor based on the court order and serve the imprisonment, or being forgave after serving specific extent of sentence; the convict can ask for restoration of prestige subsequently the last date of his criminal conviction. The offender disturbs public order and the public mind is harmed against the him/her. Or, the offender hurts people`s felling by committing the crime, for this reason people are demanding punishment for the committers (Sawlani \& Ismail, 1392) People's feelings are alleviated when the criminal is serving his/her sentence (punishment) and some time passes from the crime commitment, and society forget the hatred and resentment, which was shaped. After the implementation of the sentence, the grounds paved for the convict to remove bad memories and criminal record and continue his/her life normally in society. Because, the existence of criminal background despite the expiration of the sentence (Punishment) in the life of the convict creates obsessive and disorder, and makes it possible for him/her to commit a crime again. Usually the conditions that the law prescribes for the restoration of prestige include the execution of a full punishment, or an amnesty or mitigation of the punishment or suspension of the punishment. It is required that the due date of punishment should be met in these cases. Because, the convict cannot demand restoration of the prestige until the end, in suspension of the punishment or conditional release cases. The restoration of the prestige is discussable in felony and misdemeanor crimes; it is not deman- ded in petty crimes. Moreover, the period that law has prescribed should be passed after the end of conviction, and the convict should not commit a crime in that prescribed period as well (Sawlani \& Ismail, 1392).

\section{Types of Prestige Restoration}

There are two types of prestige restoration; Legal prestige restoration and judicial prestige restoration, which are discussed below.

\section{Legal Prestige Restoration}

Legal prestige restoring means that law sets a specific date for the crime, after which the convict's prestige is restored. The convict does not need to file an application, go to court, special conditions and formalities in Legal prestige restoration. According to the provisions of criminal procedure code the scheme of legal prestige restoration is same in enforced punishments and suspended punishments. Or, in other words, it is compulsory that the fixed duration of sentences houldelapse in both cases, and after that the prescribed legal period must also be completed. The articles (233-234) of penal code states about legal prestige restoration, as the article $234^{\text {th }}$ states: If a convict does not commit a crime during the period of suspension, the consequences of the sentence (punishment) are being destroyed and it is considered that the verdict was not issued against the person (Ministry of Justice, official Gazette, (1395) AH: $234^{\text {th }}$ article. As is clear from the above article, if the convict is sentenced to a suspended sentence or a suspension of enforced punishment, all effects of the crime vanish by the time, and the passage of time is not required, which is specified in the law for felony or misdemeanors and crimes.

\section{Judicial Prestige Restoration}

Judicial prestige restoration is carried out on the appeal of the convict thru court, who has served a certain period of time in prison. If the convict is died, the heirs of convict can demand for judicial prestige restoration.

\section{Conditions of Judicial prestige restoration}

Given to the law, there are numbers of conditions for judicial prestige restoration, which are as follow:

1) The person should be convicted to imprisonment in felony and misdemeanor crimes.

2) The exact duration of imprisonment should be expired, or the convicted should be amnestied, or the convicted should serve the specified period in conditional release. 
3) Compensation of the victim.

4) The convict can seek prestige restoration in the case of commitment of various crimes; nevertheless the time lag is calculated from the expiration date of the execution of final verdict (Rasooli \& Mohammad Ashraf, 1393).

\section{Procedures of Legal Prestige Restoration}

Judicial prestige restoration is carried out as a special procedures pattern, through which the application is prepared and submitted to a qualified court by the prosecutor. If the court rejects the application based on various reasons, the person can re-apply after one year. The court issues decision for prestige restoration if the prestige restoration application is prepared in line with conditions laid down in the law. By issuing such decree, the person is considered to have committed no crime; or the conviction history is demolished. The issued decree regarding the restoration of prestige is registered in the offices of police and prosecutor. It is worth noting that the court revokes the issued decree, if it is proved that the convicted is charged of another crime which occurred before the issuance of prestige restoration decree (Rasooli \& Mohammad Ashraf, 1394).

\section{Consequences of Prestige Restoration}

Legal or Judicial prestige restoration has number of consequences, which are as bellow:

1) The person's previous conviction history is removed, but if he/she commits another crime, he/ she are considered as a repetitive criminal.

2) The rights and privileges that were previously deprived can be re-used, as this deprivation is revoked after the restoration of prestige.

3) The restoration of prestige does not disturb the rights of third persons, what the person is obliged to do, is pay to the deserving person.

If the convict is sentenced due to commitment of a felony or misdemeanor, the prestige can be restored after full implementation of the sentence or amnesty. Compensation for the damage of the victim as ordered by the court is also comprised the full implementation of the decision. The restoration of prestige is permissible in following occasions, as stated in $362^{\text {nd }}$ article of Criminal Procedure Code:

1) The person should be charged to imprisonment in felony and misdemeanor crimes.

2) The verdict has been finalized, or the convict has already served his/her sentence, or is amnestied.
3) Punishment is fully enforced. It means that the convict has not only fully served punishment, or has been amnestied, but has also paid compensation to the victim. He/she does not owe the financial rights and obligation of individuals or the state. (Ministry of Justice, Official Gazette, 1393).

\section{Request for Prestige Restoration}

The $263^{\text {rd }}$ article of Criminal Procedure Code states regarding the request for prestige restoration that; (The convict and his/her heirs may seek prestige restoration of the court, which ruled against him/her according to ordinances of the law). The Criminal Procedure code points to two issues; firstly, it talks about the individuals that can seek for prestige restoration, and secondly it indicates the organ or court that person can claim for his right.

a) Request for prestige restoration by convict and his/her heirs.

b) Request for prestige restoration is sought of the court, which issued verdict or order against the convict.

c) Restoration of prestige is carried out in line with the ordinances of the Criminal Procedure Code. (8: $263^{\text {rd }}$ article).

In addition to this, the article $264^{\text {th }}$ of the Code states that the request for prestige restoration is carried out within taking into account the type of crime and following conditions.

1) In felony, it occurs after the execution of the sentence (Punishment), or the finishing of (6) years from the date of amnesty.

2) In misdemeanor, it occurs after the expiration of sentence (Punishment) execution, or the expiration of (3) years from the date of amnesty.

3) For repetitive criminals, the request for prestige restoration occurs after expiration the periods twice set in (1) and (2) paragraphs.

It is worth noting and required for the restoration of prestige that certain duration of time should be passed of the time of committing the crime and from the imprisonment of the convict. As we mentioned earlier the period is differing due to the nature the crime. In felony the expiration of (6) year, and in misdemeanor the expiration of (3) year is compulsory for asking prestige restoration. Considering various time periods for prestige restoration is due to the severity of crime and the main purpose of this is to eliminate the criminal signs and effects from the 
society, and to avoid the recurrence of criminal act by generating fear of committing a crime in perpetrators (Sawlani \& Ismail, 1392).

\section{The prestige restoration period for conditional released person}

If the convict is a conditional released person, the time lapse for prestige restoration is calculated from the finalized date of conditional release order. The person who enjoys the benefit of conditional release can also be benefitted from the concession of prestige restoration. However, the time calculation for prestige restoration in conditional release is discussable, and in status of conditional release the time lapse is calculating from date that order was finalized. A like felony and misdemeanor crimes that prestige restoration period was considered from the implementation of the punishment; in conditional release, the time calculating is starts from the finality of release order (Jawanmard \& Behroz, 1393).

\section{Prestige Restoration in term of multiple criminal verdicts}

If the applicant of prestige restoration is convicted to several criminal sentences in a such way that ordered sentences are applicable as series, the time elapse is be calculated from the implementation of final order. If convict has committed different crimes and sentenced to diverse punishments based on various criminal provisions, and these punishments are applicable to the convicted person one after other; in this case the time elapse calculation is counted from the execution date the final sentence against the convict (Rahimdil \& Masnoor, 1387).

\section{Application of Prestige Restoration}

Prestige restoration application contains the following contents:

a) Identity and address of the applicant.

b) Name of the court that issued final sentence, the sentence issuance date and the issued version.

c) Chargeable crime and the article of law that criminalizes the act ascribed to convicted and is cited in the decision of the court.

d) The expiry date of executive sentence or the finality date of conditional release.

The person seeking restoration of prestige shall submit the application in line with the ordinances of the law (Rahimdil \& Masnoor, 1387).

\section{Inquiry of the innards of the investigation}

The application for prestige restoration is presented to the relevant prosecutor's office; the prosecutor conducts the necessary investigation in this regard and submits his/her opinion to the relevant court within one month, citing reasonable grounds:

1) Copy of the court's verdict

2) Background of the convicted (History)

3) Inquiry report of the contents of application.

The request for judicial prestige restoration is bestowed to the relevant prosecutor's office. The Prosecutor's Office investigates the issue and submits its opinion to the relevant court within one month, citing the reasons and appendices stated in the criminal procedure Code.

\section{Re-submission of prestige restoration application}

If the prestige restoration application is rejected due to incompleteness of legal requirements, it can be resubmitted after the lapse of (1) year. As we mentioned earlier, judicial prestige restoration requires existence of some conditions, so the application prepared for judicial prestige restoration must meet the necessary legal requirements. If court rejects application for prestige restoration due to non-fulfillment of legal requirements, then the prestige restoration application could not be made again until expiration one year (Rasooli \& Ashraf, 1393)

\section{Inquest of Application}

a) The prosecutor should notify the applicant at least (7) days earlier the court session takes place, considering the distance of the route.

b) The court hears the statements of the applicant and the prosecutor during the review of prestige restoration application.

\section{We address two issues regarding the above}

a) It is essential that the applicant should be informed seven days earlier of the hearing, when the court reviews the application for judicial prestige restoration, considering the distance of the route.

b) The court hears the views of applicant and prosecutor to the application for restoration of prestige, and then decides in line with the ordinances of law (Rasooli \& Ashraf, 1393).

Issuing of verdict regarding the prestige restoration

The $371^{\text {st }}$ article of Criminal Procedure Code states on this matter.

1) When it becomes clear or proved that applicant meets the circumstances stated in this chapter, the court issues order to restore his/her prestige 
and it will be considered that applicant has not committed a crime at all.

2) The prestige restoration order is registered in the offices of prosecutor and police (Ministry of Justice, Official Gazette, 1393).

The application for prestige restoration is presented to the court. The court decides for restoration of the prestige, and declares its decision through an order, whenever it becomes evident that the specified conditions have been met during filing the application. The issuance of prestige restoration order means that applicant has not committed a crime, and this order eradicates his/her criminal background.

Moreover, the issued order regarding restoration of prestige is registered in the offices of prosecutor and police. Because, normally the criminal background of offender can be found in these two offices.

\section{Revocation of prestige restoration order}

We discuss two following issues in connection to this;

1) The court may revoke the prestige restoration order; if it is proved alongside the court that the applicant has been charged for another crime and decision was issued against the applicant, and the court was not aware of it while examining the application for restoration of prestige; or if the convict is penalized for the crime, which committed before the issuance of the prestige restoration order.

2) The court can revoke prestige restoration order on the request of prosecutor.

Founded on the above mentioned situations; the prestige restoration order is revoked in two situations, as bellow:

a) If the court discovers that the applicant is convicted for another crime as well, and the court was not aware of it while issuing the prestige restoration order.

b) The applicant is charged for the crime that he/she committed it before the issuance of prestige restoration order.

In both cases the court revokes the prestige restoration order on the request of the prosecutor. (Rahimdil \& Masnoor, 1387)

\section{Legal Prestige Restoration}

The prestige of applicant will be restored legally if he/she does not commit misdemeanor or felony in following circumstances or periods:
1) In felony; elapse of 10 years from expiration of sentence enforcement, or amnesty.

2) In misdemeanor, elapse 5 years from implementation of the sentence, or amnesty.

The request and application technique and various situations for judicial prestige restoration were discussed earlier. In this section we will discuss another type of prestige restoration, which called legal prestige restoration. According to $373^{\text {rd }}$ article of criminal procedure Code:

If the applicant does not commit another crime after the expiration of the period declared in this article or if he/she is not convicted to felony and misdemeanors crimes; His/her prestige will be restored without any request in line with the ordinances of the law. The duration for legal prestige restoration in misdemeanor and felony crimes is as follow: lapse of 10 years from expiration of sentence enforcement, or amnesty in felony crimes. Lapse (5) years from the implementation of the punishment, or amnesty in misdemeanor crimes (Rasooli \& Ashraf, 1394)

\section{Objection of Prestige restoration order}

The order of primary court on the restoration of prestige cannot be objected or appealed. In Judicial prestige restoration, the issued order is final and the parties do not have the right to appeal or object. In legal prestige restoration the law specified certain duration for legal prestige restoration, and after expiration of this duration, the prestige itself is restored and the restored prestige is not object-able. In judicial prestige restoration, the applicant himself/herself applies for prestige restoration; if the convict is died his/her heir can demand prestige restoration. Prestige restoration is carried out when the order is finalized and sentence is enforced. Similar to legal prestige restoration, an order issued by court on prestige restorations exposed to the conditions set out in the code, thus no appeal is allowed, and no one can object (Rasooli \& Ashraf, 1394)

\section{DISCUSSION:}

It is worth noting and is necessary for the restoration of prestige that an exact duration should be elapsed from the imprisonment of the convict. The conditional released person can also be profited of this rule. If the applicant has committed various crimes, and convicted to various punishments, in this case the time elapse is calculated from the execution date of final verdict. The application for judicial prestige restoration is presented to the applicable prosecutor's 
office. The Prosecutor's Office investigates the matter within a month, and submits its opinion to the relevant court, citing the reasons and attached pages stated in the Code. If the court rejects the prestige restoration application due to non-fulfillment of legal requirements, then the applicant cannot request within a year. Prestige restoration means that the convict has not actually committed any crime, and his/her criminal record and background are smashed. If the court issues order on restoration of prestige of the convicted person, this order is final and not to be appealed. The reason is obvious, because the law has determined the duration for prestige restoration, when the period elapses or ends the prestige restored itself or automatically.

\section{CONCLUSION:}

Whenever the convicted serves the sentence of his/ her conviction and the time passes since the crime was committed, the people become calm to some extent and the produced hatred against him/her is forgotten from the minds of public. The convicted also gets the chance to erase this bad memory and criminal record of his/her life and return to society as a normal human being. The convict applies for prestige restoration, in order to achieve this goal. The prestige is restored in two ways; Legal prestige restoration and judicial prestige restoration. Legal prestige restoration is same in executive and suspense punishments according to Code, however in both cases the punishments are implemented completely, and the specified period is passed. Nonetheless, the judicial prestige restoration is carried out on request of the convict who has served a certain time in prison through the court. The court issue order on prestige restoration of convict, when it realizes that the restoration of prestige is requested subject to certain conditions and in line with the law. The issuance of the decision means that the convicted person has not committed any crime or his/her conviction will expire. The law recognizes two issues regarding to prestige restoration; first the person that has the right to seek restoration of prestige; second the authority or court from which the person seeks restoration of prestige.

\section{ACKNOWLEDGEMENT:}

I wish to express my most grateful appreciation to the University authority for their kindness in supporting and permitting me to do this research.

\section{CONFLICT OF INTERESTS:}

The authors declare no conflict of interest.

\section{REFERENCES:}

1) Guldozian, Iraj, (1388). AH, Fundamentals of General Criminal Law, (1, 2, 3) Volumes, Mizan Law Foundation, Tehran, Iran.

2) Islam MN. (2020). The impact of human rights violation concerning the status of women and children in Bangladesh: a critical review, $B r . J$. Arts Humanit., 2(1), 1-13. https://doi.org/10.34104/bjah.02001013

3) Jawanmard, Behroz, (1393). AH. Criminal Procedure Code. Vol. 1, Javidana Publication house, Tehran, Iran.

https://legislative.gov.in/sites/default/files/A197402.pdf

4) Ministery of Justice, official Gazette, (1395). AH. Criminal Code. Series number (1260).

5) Ministry of Justice, Official Gazette, (1393). AH. Criminal Procedure Series Number (1132).

6) Rahimdil, Masnoor, (1387). AH. The Burden of Proof in Criminal Cases. Samt Publication House, Tehran, Iran.

7) Rasooli, Mohammad Ashraf, (1393). AH. Conditional Release, Suspension and evanescence of criminal conviction. Vol 2, Fazel Publication center, Kabul, Afghanistan.

8) Sawlani, Ismail, (1392). AH. General Criminal Law. Vol 3, Fifth Edition, Gunj Danish Publication House. Tehran, Iran. http://dx.doi.org/10.18415/ijmmu.v6i4.1223

9) Rasooli, Mohammad Ashraf, (1393). AH. Fair Trail. Saeed Publication house, Afghanistan.

10) Rasooli, Mohammad Ashraf, (1394). AH. The explanation of Criminal Procedure Code. Lemar Publication Center, Kabul Afghanistan.

Citation: Miakhil P, Naeem A, and Bahar AA. (2022). Prestige restoration according to Afghan legal system, Asian J. Soc. Sci. Leg. Stud., 4(1), 12-17. https://doi.org/10.34104/ajssls.022.012017 @ @ ( 